\title{
The Politics of Personal Naming in South Africa
}

\author{
Robert K. Herbert
}

\section{State University of New York, Binghamton}

The relationship between naming and sociocultural meaning among the peoples of southern Africa is changing. A comparison of names bestowed in two time periods shows how patterns of naming reflect sociocultural changes, including the demands of a centralized bureaucracy and the urbanization of populations. The ways in which systems of naming responded to recent political events in South Africa is examined. In line with the traditional history-keeping function of personal names, there is a greater incidence of political names for children, especially boys, born after 1990.

\section{Introduction}

The study of personal names and naming practices has traditionally rmed part of the recognized domain of social anthropologists in so far social categorization is served by the system of names (Lévi-Strauss 366). More recently, personal names have attracted attention for what ey reveal to the analyst about the values, thoughts, hopes, fears, and sasts of the namers, i.e., those who bestow names upon themselves and hers. This approach recognizes the act of naming as an explicitly nguistic act; names are thus sociolinguistic data par excellence-for it through naming and the systems of address and reference within hich they are embedded that members of the speech community reveal e complexities of social relations, roles, and statuses. The name that am allowed to call you reveals much about our relationship, about the lative distribution of power and status, and about the roles which are sing played at any moment.

There is, however, another reason why names are of interest to the ciolinguist. In addition to revealing something about the one who gives ames, personal names at the societal level provide insight into the 
operative system of cultural values within the community. To take a specific example, the facts that (1) English names for females are often derived from male names whereas the reverse pattern never occurs (e.g., George > Georgette; Robert > Roberta), (2) labels for virtues, flowers, gems and other objects name girls but not boys (e.g., Grace, Lily, Ruby), and (3) fathers' names are more often bestowed upon sons than mothers' names upon daughters (as illustrated by the traditional use of suffixes such as $J r$. and III, IV among boys only) tell us much about Anglo-Saxon cultural values. Cultural values are, of course, not static. They respond to internal and external pressures over time. Traditional values may be modified or replaced by new ones.

If the relationship between personal names and cultural values sketched above is real, the onomastic analyst should expect to find changing values reflected in changing patterns of naming. Such study of changes in names and naming systems might appropriately be termed dynamic onomastics.

This article is concerned exclusively with personal names given within African communities in South Africa. It is worth noting that the dynamic nature of naming systems has not received much attention in the ethnographic literature, which has tended to offer brief descriptions of indigenous naming systems as static; none of the great ethnographers of southern Africa (e.g., Bryant 1929; Junod 1927; Mönnig 1967; Soga 1932) do much more than provide a rough typology of names. When they do go beyond such a typology, it is to provide greater detail on the names bestowed after "unusual" births, e.g. twins, children born into families in which previous children have not survived, children born out of wedlock, etc. They neglect the workings of the larger system.

\section{Typological Changes in African Naming}

The greatest typological shift within African systems of naming resulted, of course, from culture contact with colonial power, values and languages. In addition to the introduction of the so-called "Christian name," whose history is so well-known that it need not be reviewed here, culture contact and the demands of colonial bureaucracy resulted in the introduction of European-type surnames within African populations. One should carefully distinguish between cases in which the system of surnames was grafted onto an indigenous system of second names and those in which it was created ex nihilo. The introduction of 
surnames within a population is certainly not unique to Africa. Spencer (1961), for example, described how the Name Law of 1934 required every Turkish citizen to register a surname and the "wild scramble for appropriate surnames" that took place as a result. In the African context, one notes how clan names, praise names, patronyms, eponyms, placenames, and even colonial surnames have jointly supplied the needs of a bureaucracy that demands at least two names for classification, the last of which is expected to indicate descent. There are exceptions to the last generalization, e.g., groups in which the first name is the European name and the "last name" is actually the African given name, or-particularly among groups who have been in contact with Islamic tradition-the father's given name.

Focusing exclusively on personal names, the introduction of Christian names itself produced an important typological change in many naming systems. To take one example, individuals formerly received one dominant name at birth whereas two names-one African and one European-became the norm shortly after the establishment of colonial power. One sees how changes in cultural values were expressed in the relative dominance of the African and European-language names. Owing to inconsistencies in the keeping of records, it is impossible to quantify and trace the relative prominence of European and African names as birth labels. It seems that the prominence of European names quickly established itself throughout colonial Africa, and it is not unusual to find adults who bear two given names, both of them European. These individuals have no African name, reflecting their parents' acceptance of colonial hegemony. This pattern is virtually non-occurrent among children in South Africa today. Social and political consciousness of the past twenty years has led to a greatly reduced role-if not outright rejection-of foreign names. The very label attached to such names reflects this change in attitudes: they are often referred to not as Christian names or school names but rather "slave names," and one suspects that anyone who classes them as slave names is unlikely to bestow one upon a child. Note, however, the typological change that has occurred: many parents, though they eschew European names, still bestow $t w o$ personal names upon their offspring-both of them African and one designated by the parents as a "school name." Though it is difficult to demonstrate, the impetus for the maintenance of this pattern may be the very frequent identification of individuals by two initials plus 
surname. That is, colonial names are rejected, but a pattern introduced by contact (first name + middle name + surname) persists. The demise of colonial naming patterns has been noted throughout Africa (e.g., Omari 1970; Ekpo 1978), but the desire to eliminate foreign names and to restore an authentic naming system is certainly not unique to Africa. Such moves often follow periods of socio-political awareness in which traditional identity is called upon to assert itself. The case of Turkey is again instructive: following the emergence of modern Turkey, Quranic and Ottoman Turkish names were dropped in favour of "pure" Turkish names (Spencer 1961, 212).

\section{Meaningfulness and Uniqueness}

The so-called Christian names were never well-integrated into indigenous systems of naming in southern Africa since such names lack one essential criterion of names in most African societies: meaning. It is a virtual universal among the peoples of sub-Saharan Africa that personal names are semantic units. Certainly, if one looks at any of the societies of central or southern Africa, names are lexical units which may be semantically and morphologically decomposable into smaller units. These meanings are almost never obscure; it is extremely rare to find people who cannot give the meaning of their own name or of any other name in the community. Lexical meaning is not to be confused with significance; the latter term relates to the reason for choosing a particular name, i.e., what it means within the sociocultural fabric. The significance of a name may indeed be obscure. For example, the Zulu name Phakatikwezinja 'among the dogs' looks at first like a derogatoryprotective of the sort given in many societies to ward off spirits who might harm the child. In fact, the name was bestowed by a father as a praise to indicate that his son is the only true man: compared to him, all others are like dogs. Similarly, the significance of a name such as Zibuyile 'they have returned' is obscure since it requires special sociocultural knowledge to recognise that the class prefix $z i$-refers to cattle which come to the family as bridewealth upon the marriage of a daughter; the name is typically bestowed on a girl born into a family with many sons. In neither of the latter examples, however, is the lexical meaning of the name opaque.

European names are deficient in this very regard: they, like other monomorphemic words of any language, are arbitrary labels. They may 
have history, but they generally have no meaning. In some colonial contexts, among the Pende of Zaire for example, French proper names were never accepted for this reason. Instead, French common nouns were borrowed as personal names (Ndoma 1977, 92). This strategy preserves the criterion of name meaningfulness and also enables people to continue the tradition of bestowing names relating to events and conditions at the time of birth.

The change in name typology discussed here involves only the personal names drawn from African languages. Although there is some variation from one linguistic group to another in southern Africa, there are two basic systems of personal naming. In the first; traditional names, as noted above, have meaning; it is most usual for the name selected for a child to relate to conditions or events surrounding the time of birth. The other type of name system is for family or "commemorative" names to be passed from one generation to another, most typically with names shared by every other generation, i.e., the same names are used for members of the grandparents' and grandchildren's generations. The former system is generally observed among the Nguni peoples (Zulu, Xhosa, Swati) and the latter among the Sotho-Tswana. Note that although these two systems are typologically quite distinct, they share the common feature of serving a history-keeping function. In the first case, the name locates the birth within a particular temporal context, and in the latter case the bearer is located within a familial context.

It should also be noted here that the characteristic of name uniqueness operated in many central and southern African societies. In the Nguni-type systems, such a characteristic followed from the system itself; there is almost no incidence of name repetition in the earliest documents. In the Sotho-Tswana system, there is typically not more than one living bearer of a given name. ${ }^{1}$ The characteristic of name uniqueness is being weakened today as many bourgeois parents have adopted the European custom of naming children, particularly sons, after themselves.

In the two anthroponymic systems of southern Africa, the distinction is made between personal names that stress the individual's uniqueness and names that draw attention to social position, or explicitly mark the link with other individuals. According to Lévi-Strauss (1966), both name systems serve classificatory functions. It is possible to link differences in Nguni and Sotho-Tswana naming patterns to differences in residential 
patterns and preferential marriage patterns among the Sotho-Tswana. For the Nguni, who live in scattered independent homesteads, personal names serve to individuate members of a single patrilineal group. From the perspective of marriage patterns, it is the absence of the izibongo (clan name) of the four grandparents that determines suitable partners. For the Sotho-Tswana, living in large settlements, personal names mark an individual as belonging to a particular patrilineal group and it is membership in particular groups that marks someone as a preferred/suitable marriage partner. Thus, the basic difference between the two types of naming systems can be related to functional reasons involving the exploitation of the naming system as a resource within the two types of communities (Herbert 1996).

\section{Developing a Name Repertoire}

The basic question to be addressed here relates to the history-keeping function of personal names. Specifically, to what extent do names given in the 1990s offer any contextualization of the child's birth?

The first issue we face is the question of whether or not modern names represent a departure from traditional naming practices. We have documented elsewhere (Herbert and Bogatsu 1990; Herbert 1996) the emergence of a name repertoire, a stock of recurrent names which are found within the African languages, particularly in urban contexts. The existence of such a repertoire of names which occur with high frequency testifies to the weakening of name uniqueness as a system criterion. In broad outline, these names relate to the emotional state of the namegiver, particularly the mother, or to a display of Christian values. In the first case, there are names such as Zulu Jabulani 'be happy', Njabulo, Gugu and Gugulethu '(our) treasure', Thokozile 'rejoiced', Themba 'hope' and Tswana Itumeleng 'rejoice', Boitumelo 'happiness' Lehogang 'be grateful'. In the second category, there are Zulu names such as Sipho 'gift', Sibusiso 'blessing', Sibongile 'we are grateful', Bonginkosi 'thank the Lord', and Tswana Neo 'gift' Tebogo 'gratitude', and Thapelo 'prayer'. Although the names may not explicitly refer to God, the namegivers routinely mention God in their explanation of why they chose a particular name. Note that the history-keeping function of names is completely missing in this inventory. These names relate to states (emotional and religious) rather than events surrounding the time of birth. The recurrence of these names throughout urban centers in South 
Africa points to an emerging stock of names which is drawn upon to name new children.

A further demonstration of the dissociation between the act of naming and birth circumstances comes from the fact that many informants are perfectly willing to reveal names that they would like to bestow on their future children. The reasons they give for their preferences are the same as those reported by actual namegivers; e.g., they would be happy to have a child, expressing that a child is a gift from God, as well as liking the "sound" of a particular name. The existence of such preferences and the willingness to speculate about names of future children are completely foreign to traditional values, which insisted that no preparations for childbirth be undertaken. ${ }^{2}$ In this regard, the system of naming has become more like its European counterparts, although the criterion of name-meaningfulness continues to sharply differentiate between the European and African systems. What is important to stress at this point, however, is that such a system-although African in its content-is not "traditional" in the sense that it continues historical patterns. It is, of course, uniquely African in the sense that the formatives are taken from African languages.

\section{Political Names}

At the same time that a stock of urban names has developed, there are certainly names bestowed today that actively reflect conditions and social relations operative at the time of birth. In this case, we may ask the extent to which the analyst can assert that the history-keeping function of personal names has been maintained. In order to investigate this issue, the subtype "political names," names referring directly or indirectly to political events and personalities, was selected for examination. Several reasons motivated the choice of this particular subtype. First, politically-inspired names should be readily recognizable as such, either transparently, by the meaning of the name itself, or by the explanation provided by the namegiver. Second, the prominence of political events over the past 20 years in South Africa, but particularly since February 1990, is great enough to expect these events to be reflected in personal names bestowed on children. Third, studies of naming patterns elsewhere in the world have shown that major political reorientations are often directly reflected in child naming. For example, following the 1952 Revolution in Egypt, the names Gamal, Nasr, and 
Abdel Nasr become popular, and one child was named Sukarno (Callender and el Guindi 1971, 28). Similarly, Omari (1970, 66) reported the occurrence of such political names in post-independence Tanzania: Uhuru 'freedom', Sabasaba '7-7' (referring to Independence Day, July 7), Jamhuri 'republic', Azimio 'declaration/program', and Muungano 'unity/cooperation'. Zhongti and Millward (1989) noted major shifts in the names given to children during and after the Cultural Revolution in the People's Republic of China. The system of personal naming in Chinese is rather like that of African languages to the extent that great creativity is possible in naming, since there are no traditional restrictions on the pool of given names and names often reflect contemporary conditions. Stahl (1992) compared two groups of Israeli schoolchildren and showed how ideological differences among the parents manifested themselves in two name pools.

In order to test whether there has been an upsurge in political naming within South Africa, a data base of urban names was collected. The base was restricted to urban names since informal observation had suggested that political names might have a higher incidence there than in the rural areas. Names for children born in the period 1980-1985 (Group A) and for children born since February 1990 (Group B) were collected during 1993 from mothers who were attending child care clinics in Soweto, a large township adjacent to Johannesburg. Group A contained 178 names ( 87 male, 91 female) and Group B contained 203 names (110 male, 93 female). Thus, there were 381 names in all (197 male and 184 female).

The reason for selecting the first time period rather than an earlier one was that it allowed us to sample single families whose children might span the time frames of interest. In the final analysis, it was not possible to restrict the study to such families, but because of protracted fecundity there is significant overlap in the parental generation for the two groups. Previous research on naming in urban areas has revealed that parents are the primary namegivers, regardless of the traditional pattern of namegiving, where grandparents often served as namegivers.

The following information was collected along with each name: linguistic/cultural group of the mother and father, date of child's birth, sex, child's name, English name (if any), reason for name choices, identity of namegivers. A preliminary analysis of the given names provided a two-way classification: political vs. non-political. For purposes of classification, we defined as political any name referring or 
alluding to political events, orientations and personalities. The political names are generally easy to identify, e.g., Tokologo, Tokoloho, Nonkululeko, Nkululeko 'freedom', Mandela, Comrade, Communist, Samora, Khululisizwe 'release the nation', Lungelo 'rights', Shayimpimpi 'kill the spy', Nqobile 'we've conquered', Ginyibunu 'swallow the Boer'. In a number of instances, it is only the explanation of the name choice that identifies it as a political name, e.g., Ntuthuko (Zulu) 'progress' refers to the child's father's being chosen as a member of the ANC executive, Sivumelwano (Zulu) 'agreement' names a child who was born in the month of the first CODESA (Congress for a Democratic South Africa) meeting, and Afrika-Karabo 'Africa-answer'. In the latter case, the father noted that this child will fight apartheid and answer for Black Africans; he also remarked that the initials A.K. implied the AK47 assault rifle. Finally, it should be noted that some names which look political at first sight are non-political when the intention of the namegiver is considered, e.g., several tokens meaning 'freedom' refer to "freedom from the accusations of my in-laws," release from a difficult childbirth, a desire that the child will provide the mother with independence from her in-laws, and the like. Thus the same name is sometimes classed as political and sometimes not, depending on its referent.

Perhaps not surprisingly, there is a significantly higher incidence of political names in the post-1990 sample as shown in table 1. In particular, almost one-fourth of the names in that group are political as opposed to one-thirteenth in the 1980-85 sample. ${ }^{3}$

Table 1. Political and Non-Political Names at Different Times

\begin{tabular}{cccccc}
\hline & \multicolumn{2}{c}{ Political } & \multicolumn{2}{c}{ Non-Political } & Total \\
Time & $\mathrm{N}$ & $\%$ & $\mathrm{~N}$ & $\%$ & \\
$1980-85$ & 14 & 7.9 & 164 & 92.1 & 178 \\
After 2/90 & 48 & 23.6 & 155 & 76.4 & 203 \\
\hline
\end{tabular}

$\chi^{2}=17.34 \mathrm{p}<.001$

Thus, even at this preliminary level, one can see how the shift to a repertoire of given names is progressive but far from complete.

Other striking facts arise from these data. The distribution of political names is clearly sex-linked. Specifically, boys are significantly 
more likely than girls to bear political names in both time periods, as shown in table 2. Note especially the dramatic differences in Group B among the children's names in the more recent time period.

Table 2. Political Names and Sex of Bearer in Two Time Periods

\begin{tabular}{|c|c|c|c|c|c|}
\hline & \multicolumn{2}{|c|}{ Boys } & \multicolumn{2}{|c|}{ Girls } & \multirow[t]{2}{*}{ Total } \\
\hline & $\mathbf{N}$ & $\%$ & $\mathbf{N}$ & $\%$ & \\
\hline $1980-85$ & 10 & 71.4 & 4 & 28.6 & 14 \\
\hline After $2 / 90$ & 43 & 89.6 & 5 & 10.6 & 48 \\
\hline
\end{tabular}

$\chi^{2}=1.6 \mathrm{p}<.10$

Further, note in table 3 that almost $40 \%$ of the names bestowed upon boys in the period since February 1990 are political.

Table 3. Distribution of Name Types since 1990

\begin{tabular}{lccccc}
\hline & \multicolumn{2}{c}{ Political } & \multicolumn{2}{c}{ Non-Political } & Total \\
& $\mathrm{N}$ & $\%$ & $\mathrm{~N}$ & $\%$ & \\
Boys & 43 & 39.1 & 67 & 60.9 & 110 \\
Girls & 5 & 5.4 & 88 & 94.6 & 93 \\
\hline
\end{tabular}

$\chi^{2}=31.74 \mathrm{p}<.001$

The prominence of political events in this period has dramatically affected naming patterns. That boys should preferentially bear political names is not surprising since previous research on urban names has revealed that girls are significantly more likely to bear emotion-related names whereas boys tend to bear names commemorating a family member or roles within the family (Herbert and Bogatsu 1990). That is, boys are given names reflecting events and ideas that "matter." 4

As noted above, information on the identity of the namegiver was also collected in this survey. The majority of urban names were chosen byparents. In this sample, fathers and mothers accounted for threefourths of the names (and contributed approximately equally); the remaining names were contributed by grandparents, aunts, uncles, or others. 
Although fathers and mothers provided roughly equal numbers of urban names, there are significant links between the identity of the namegiver, the sex of child, and the type of name bestowed. There is a general association between the sex of the namegiving parent and the sex of the child. Ignoring the "Other" namegiver category, which contributes equal numbers of male and female names, fathers are significantly more likely to choose names for boys and mothers to choose names for girls, as shown in table 4.

Table 4. Sex of Namegiving Parent and Sex of Child

\begin{tabular}{lccccc}
\hline & \multicolumn{2}{c}{ Boys } & \multicolumn{2}{c}{ Girls } & Total \\
Namer & $\mathrm{N}$ & $\%$ & $\mathrm{~N}$ & $\%$ & \\
Father & 104 & 68.0 & 49 & 32.0 & 153 \\
Mother & 45 & 33.6 & 89 & 66.4 & 134 \\
\hline
\end{tabular}

$\chi^{2}=33.86 \mathrm{p}<.001$

Thus fathers are approximately twice as likely to name their sons and mothers their daughters. The contribution of fathers to the category of political names is overwhelming $(49 / 62 ; 79 \%)$ and almost all of this contribution, as noted previously, is bestowed upon their sons. Ignoring 3 political names given by Other, the distribution of political names is shown in table 5 .

Table 5. Distribution of Political Names by Sex of Parent/Child

\begin{tabular}{lccccc}
\hline & & Sons & \multicolumn{2}{c}{ Daughters } & Total \\
& $\mathrm{N}$ & $\%$ & $\mathrm{~N}$ & $\%$ & \\
Fathers & 44 & 89.8 & 5 & 10.2 & 49 \\
Mothers & 07 & 70.0 & 3 & 30.0 & 10 \\
\hline
\end{tabular}

$\phi=.217 \chi^{2}=4.7089 \mathrm{p}<.05$

The Fall of European Names

Another measure that might be used to gauge changing political awareness as revealed in naming practices is the incidence of European names bestowed upon children in the two periods. The history of a twoname pattern has been treated elsewhere (Koopman 1976; Dickens 1985; 


\section{Names 45.1 (March 1997)}

Netshiheni 1994) and there is no need to review it here. The essential point for present purposes is that over the past 75 years it has become the norm to bear two (or more) names, one of which is a European name, a "school name." Originally, many of these school names were bestowed by teachers when children entered mission education, but the pattern gradually changed and European names were given at birth, in addition to African names. One might expect that the increase in political names in Group B would be matched by a decrease in English names, i.e., that both name types might serve as a measure of politicization. In fact, there has been a small decrease in the incidence of English names during the period considered, but that difference is not statistically significant (table 6).

Table 6. Distribution of European Names in Groups A and B

\begin{tabular}{cccccc} 
& \multicolumn{2}{c}{ With English Name } & \multicolumn{2}{c}{ Without English Name } & Total \\
& N & $\%$ & N & $\%$ & \\
$1980-1985$ & 67 & 37.6 & 111 & 62.4 & 178 \\
After $2 / 90$ & 65 & 31.7 & 138 & 67.3 & 203 \\
\hline
\end{tabular}

$\chi^{2}=1.32 \mathrm{p}<.250$

Similarly, there is a slightly lower frequency (though not statistically significant) of English names being given to boys. Finally, as one might expect, there is a sharply diminished frequency of English names being given to those children who bear political names (table 7). That is, the same political consciousness that leads parents to bestow political names upon their children leads them to reject "slave names," and this difference is highly significant.

Table 7. Association of Political and European Names

\begin{tabular}{lccccc}
\hline & \multicolumn{2}{c}{ Political } & \multicolumn{2}{c}{ Non-Political } \\
& $\mathrm{N}$ & $\%$ & $\mathrm{~N}$ & $\%$ & Total N \\
English Name & 9 & 6.8 & 123 & 93.2 & 132 \\
No English Name & 53 & 21.3 & 196 & 78.7 & 249 \\
\hline
\end{tabular}

$\chi^{2}=13.25 \mathrm{p}<.001$ 
There are other patterns apparent in the data which are also relevant to a general discussion of changes in name types. In particular, there is a shift in the actual tokens of English names bestowed today. Koopman $(1976,20)$ reported that many of the more popular names among Europeans in South Africa (e.g., Sandra, Diane, Glen, Gary) were not found among Zulu people; however, there was some noticeable movement in this direction, especially in urban areas. Another category worthy of mention is that in which African names are calqued and "new" English names are created: Zulu Nhlanhla becomes Lucky and Sithembiso becomes Promise. More recently, there is a notable increase in the incidence of "meaningful" English names, not all of which are translations of African names. For example, Fiancé, Gladness, Pride, Given, Treaty, Fortunate, Geography, Kingdom, Doctor, Professor, and Pleasure are all attested in the data. The increased incidence of such names brings European-based names into accord with the central African criterion of name meaningfulness.

\section{Conclusion}

The data presented here show that there is a close relationship between naming and sociocultural meaning in South Africa; the system of naming and naming patterns reflects social organization and cultural values. This relation is seen in the evolution of a name typology which accommodates the demands and values of a colonial bureaucracy, in the rise and fall of foreign language names, in the development of a repertoire of recurrent names in the African languages, and in the response of naming patterns to heightened prominence of political events since 1990, reflecting the traditional history-keeping function of personal names. In all of these changes, it is clear that naming patterns are closely interrelated with social and cultural patterns.

\section{Notes}

1. This feature has occasionally been linked to ideas of reincarnation, but there is no reason to accept such a suggestion since there is no notion that the namesakes are "the same person." Rather, the intention is to honor the original bearer of the name, who may offer special protection to the namesake.

2. E.g., "Chez les ba-Ronga, au contraire, il serait de mauvais augure de chercher un nom pour un enfant qui n'a pas encore vu le jour. Ce serait attirer dangereusement sur l'enfant l'attention des esprits malfaisants qui peuplent l'air ambiant" 


\section{Names 45.1 (March 1997)}

(Guye 1920, 64). ["Among the Ronga people, by contrast, one would be ill-advised to consider names for an unborn child. Such actions would dangerously attract the attention of evil spirits in the atmosphere."]

3. In a study of Northern Sotho and Tswana personal names given to children born between 1975 and 1989 in Johannesburg, Herbert and Bogatsu (1990) found only two political names in a sample of 113 .

4. In some of the societies of southern Africa, names are structurally sex-typed, e.g., Zulu (Koopman 1979). The different treatment of males and females with regard to English personal names is also interesting. For example, although the earliest records of English names among African groups show that names from the Bible and calendar of saints are equally distributed between the sexes, the shift to other types of English names (historical, place, values, flowers as well as ordinary common nouns) occurs first for girls. Although the point is not made by Dickens (1985), it is interesting to note that of the 407 names recorded in her data for 1929 $(197 \mathrm{~m}, 210 \mathrm{f})$, slightly more than $50 \%$ of the male names are "religious" compared to $22 \%$ of female names.

\section{References}

Bryant, A.T. 1929. Olden Times in Zululand and Natal. London: Longmans.

Callender, C. and F. el Guindi. 1971. Life-crisis Rituals among the Kenuz. Cleveland: Case Western Reserve University Studies in Anthropology 3.

Dickens, Sybil.M. 1985. Western Influences on the Zulu System of Personal Naming. Unpublished M.A. thesis, Rhodes University.

Ekpo, Monday U. 1978. Structure in Ibibio Names. Names 26: 271-284. Guye, Henri. 1920. Des noms propres chez les ba-Ronga. Bulletin de la Société Neuchâteloise de Géographie 29: 62-74.

Herbert, Robert K. 1996a. Personal Naming and Social Organisation: the Comparative Anthroponomy of Southern Africa. Paper presented at XIX International Congress of Onomastic Sciences, Aberdeen, Scotland.

. 1996b. "The Dynamics of Personal Names and Naming Practices in Africa." Namenforschung. Name Studies. Les Nomes Propres. Ed. Ernst Eichler, Gerold Hilty, Heinrich Löffler, Hugo Steger and Ladislav Zgusta. Berlin: Walter de Gruyter, 1222-1227.

Herbert, Robert K. and Senne Bogatsu. 1990. Changes in Northern Sotho and Tswana Personal Naming Patterns. Nomina Africana 4: $1-19$. 
Junod, Henri A. 1927. The Life of a South African Tribe. London: Macmillan.

Koopman, Adrian. 1976. A Study of Zulu Names with Special Reference to the Structural Aspect. Unpublished B.A. Hons. dissertation, University of Natal, Durban.

. 1979. "Male and Female Names in Zulu." African Studies 38: 153-166.

Lévi-Strauss, Claude. 1966. The Savage Mind. London: Weidenfeld \& Nicholson.

Mönnig, H.O. 1967. The Pedi. Pretoria: van Schaik.

Ndoma, Ungina. 1977. Kongo Personal Names Today: a Sketch. Names 25: 88-98.

Netshiheni, S. Angelina. To appear. Names and Other Forms of Address among the VhaVenda. South African Journal of African Languages.

Omari, C.K. 1970. Personal Names in Socio-cultural Context. Kiswahili 40: 65-71.

Soga, John Henderson. 1932. The Ama-Xosa: Life and Customs. Lovedale: Lovedale Press.

Spencer, Robert F. 1961. The Social Context of Modern Turkish Names. Southwestern Journal of Anthropology 17: 205-218.

Stahl, Abraham. 1992. Children's Names as a Reflection of Ideological Differences among Israeli Parents. Names 40: 283-294.

Zhongti, Lu with Celia Millward. 1989. Chinese Given Names since the Cultural Revolution. Names 37: 265-280. 